\title{
The Adaptive Radiation of Cichlid Fish in Lake Tanganyika: A Morphological Perspective
}

\author{
Tetsumi Takahashi ${ }^{1}$ and Stephan Koblmüller ${ }^{2}$ \\ ${ }^{1}$ Laboratory of Animal Ecology, Graduate School of Science, Kyoto University, Kitashirakawa-Oiwake, Sakyo, Kyoto 606-8502, Japan \\ ${ }^{2}$ Department of Zoology, University of Graz, Universitätsplatz 2, 8010 Graz, Austria
}

Correspondence should be addressed to Tetsumi Takahashi, tetsumi@terra.zool.kyoto-u.ac.jp

Received 30 December 2010; Accepted 21 February 2011

Academic Editor: R. Craig Albertson

Copyright (c) 2011 T. Takahashi and S. Koblmüller. This is an open access article distributed under the Creative Commons Attribution License, which permits unrestricted use, distribution, and reproduction in any medium, provided the original work is properly cited.

\begin{abstract}
Lake Tanganyika is the oldest of the Great Ancient Lakes in the East Africa. This lake harbours about 250 species of cichlid fish, which are highly diverse in terms of morphology, behaviour, and ecology. Lake Tanganyika's cichlid diversity has evolved through explosive speciation and is treated as a textbook example of adaptive radiation, the rapid differentiation of a single ancestor into an array of species that differ in traits used to exploit their environments and resources. To elucidate the processes and mechanisms underlying the rapid speciation and adaptive radiation of Lake Tanganyika's cichlid species assemblage it is important to integrate evidence from several lines of research. Great efforts have been, are, and certainly will be taken to solve the mystery of how so many cichlid species evolved in so little time. In the present review, we summarize morphological studies that relate to the adaptive radiation of Lake Tanganyika's cichlids and highlight their importance for understanding the process of adaptive radiation.
\end{abstract}

\section{Introduction}

With an estimated number of about 3000 species, distributed from Central and South America, across Africa to Madagascar and southern India, cichlid fishes (Cichlidae) represent the most species-rich family of vertebrates, accounting for about $10 \%$ of today's teleost diversity $[1,2]$. Throughout their distribution range cichlids have repeatedly demonstrated their capacity of forming adaptive radiations-explosive speciation with niche partitioning (reviewed in [3]) generating an outstanding variation of body shapes, colour patterns and behaviour, and an enormous diversity of trophic and ecological specializations [4-6], which attracted numerous evolutionary biologists and established them as one of the prime model systems in evolutionary biology (e.g., [7-9]), but the greatest diversity of cichlid fishes is found in the East African Great Lakes [2].

Although endemic cichlid species assemblages are known from most East African lakes, the largest lakes Tanganyika, Malawi, and Victoria harbour a particularly rich fauna of cichlid fishes, with an estimated number of $250-800$ species in each lake $[1,2]$. Thus, the number of species seems to be correlated with lake size, congruent with the expectation that species diversity increases with habitat heterogeneity and with the opportunity for isolation by distances and allopatric diversification [9]. Because of high degrees of endemism (95-99\%), these cichlid radiations most likely originated via intralacustrine speciation $[1,7,10]$. With an estimated age of 9-12 Myr [11], Lake Tanganyika is by far the oldest of these lakes, and thus harbours the morphologically, behaviourally, ecologically, and genetically most diverse species assemblage [1, 2, 12-15], although the number of species is the smallest. Currently 200 valid species are recognized [10] with several more awaiting scientific descriptions such that the total number of Lake Tanganyika's cichlid species has been estimated to 250 [1]. These 200 species have been classified into 12 [16] or alternatively 16 [17] tribes, largely supported by molecular data [10].

The specialized, diverse morphologies of these fish appear to be the result of adaptations in their respective niches [18], and thus, these fish are regarded as ideal model system for the study of adaptive radiation $[4,8,9]$. Schluter [19] defined adaptive radiation as "the differentiation of a single ancestor into an array of species that inhabit a variety 
of environments and that differ in traits used to exploit those environments," and employed four features as criteria to detect adaptive radiation: (1) common ancestry, (2) phenotype-environment correlation (empirical evidence of correlation between the diverse phenotypes of descendant species and their divergent environments), (3) trait utility (experimental or theoretical tests of performance or fitness of a trait in its corresponding environment), and (4) rapid speciation. The first and fourth criteria are the subject of phylogenetic analyses of the species assemblage. The second and third criteria are to find adaptive phenotypes that differ between species as a result of divergent natural selection. These adaptive phenotypes may have caused reproductive isolation between species as byproduct (ecological speciation, e.g., $[20,21])$ or allowed co-occurrence of two or more closely related species at the same place and in the same time (resource partitioning, e.g., [22, 23]).

Within the Lake Tanganyika cichlid species flock species and species groups differ in many morphological traits. Numerous morphological studies on Lake Tanganyika cichlid fish have been published in the past. In this short review, we summarize the findings from these studies and highlight their importance for understanding the process of adaptive radiation.

\section{A Quick Overview on Large-Scale Phylogenetic Patterns and the Age of the Species Flock}

The first molecular phylogeny of Lake Tanganyika cichlids was published by Nishida in 1991 [32]. This allozyme-based phylogeny resolved the relationships of 20 species representing all Lake Tanganyika cichlid tribes and suggested that the Lake Tanganyika cichlids were polyphyletic. Subsequently, many molecular phylogenetic studies have been published, such that, in contrast to the situation in the much younger cichlid species flocks of Lakes Malawi and Victoria, we now have rather precise knowledge on the phylogenetic relationships within the Lake Tanganyika cichlid species flock and the relationship among African lacustrine and riverine cichlid faunas (Figure 1) (reviewed by [8-10]).

With the exception of Tylochromis polylepis and Oreochromis tanganicae, the Lake Tanganyika cichlids evolved from a common ancestor after the formation of the lake 9-12 Ma [24, 27, 33]. These fish are thought to have rapidly radiated within the lake, which fulfils the first and fourth criteria of adaptive radiation presented by Schluter [19] (common ancestry and rapid speciation). Tylochromis polylepis and $O$. tanganicae colonized the lake only recently, thus establishing themselves in an already mature adaptive radiation $[25,31]$. Excluding these species, the Lake Tanganyika cichlid species flock comprises at least six major lineages [27]. Two of these lineages comprise many morphologically highly diverse species [34]. The substrate-brooding tribe Lamprologini consists of about 80 species endemic to the lake, plus eight species that colonized the Congo River [35] and one species that colonized the Malagarazi River [36] after the intralacustrine radiation of this tribe $[37,38]$.
The mouth-brooding C-lineage (sensu [24]) includes about 100 endemic species assigned to six [16] or ten [17] tribes (species numbers, phylogenetic relationships, and biological characteristics of tribes are reviewed in [10]). Whereas the monophyly of each tribe is well supported, the phylogenetic relationships among the tribes are still largely unresolved, indicating rapid diversification and adaptation to particular ecological niches at the onset of the Lake Tanganyika radiation. The Tropheini, one of the endemic mouth-brooding tribes, were shown to be nested within the haplochromines, the most species-rich lineage that also includes the species flocks of the remaining East African Great Lakes and the majority of the northern, eastern, and southern African riverine cichlid species but originated in the course of the primary Tanganyika radiation $[29,30]$. The simultaneous radiation of the Lamprologini and the C-lineage was probably triggered by the onset of deep-water conditions in Lake Tanganyika about 5-6 Ma (primary lacustrine radiation) $[27,30,38]$. Alternative hypotheses [39, 40] suggest a twoto fivefold older age for the Lake Tanganyika radiation which would considerably predate the establishment of a real lacustrine habitat $[11,41,42]$ and imply that the onset of the radiation has happened in a riverine environment, a habitat generally considered as not suitable to host a radiation [43]. The biological characteristics of the Lake Tanganyika cichlid species assemblage with a clear resource partitioning between most tribes and the relative age of the East African cichlid species flocks strongly argue for the Lake Tanganyika radiation to have happened in a single deepwater lake [10, 30].

Unlike for the younger Lakes Malawi and Victoria molecular phylogenies of Lake Tanganyika cichlids are typically well resolved, with most species, genera, and tribes being resolved as monophyletic, indicating that lineage sorting has been largely completed. Thus, it has been assumed that these molecular phylogenies (typically based on mitochondrial genes) do closely approach the true species trees although the placement of some taxa was inconsistent with taxonomy [44-46]. Recent evidence from complementary analyses of nuclear DNA, however, clearly demonstrated that, despite being well resolved, the mitochondrial phylogenies do not necessarily reflect the true phylogenetic relationships but might be severely misleading due to ancient incomplete lineage sorting, ancient (and recent) introgression, and even hybrid speciation [26, 38, 47-53]. Nevertheless, mitochondrial phylogenies have been and are still used as proxies of species trees in comparative approaches to study the interaction and evolution of biological traits in a phylogenetic context (e.g., [54-57]), thus potentially introducing an error in inferred evolutionary patterns.

\section{Adaptive Morphology}

The evolutionary success of cichlids has been attributed to the interaction of extrinsic environmental factors and intrinsic species-specific traits. Some of these intrinsic traits might be naturally selected (e.g., the trophic morphology, body size, body shape, and visual pigments), whereas others are predominantly sexually selected (e.g., body colouration, 


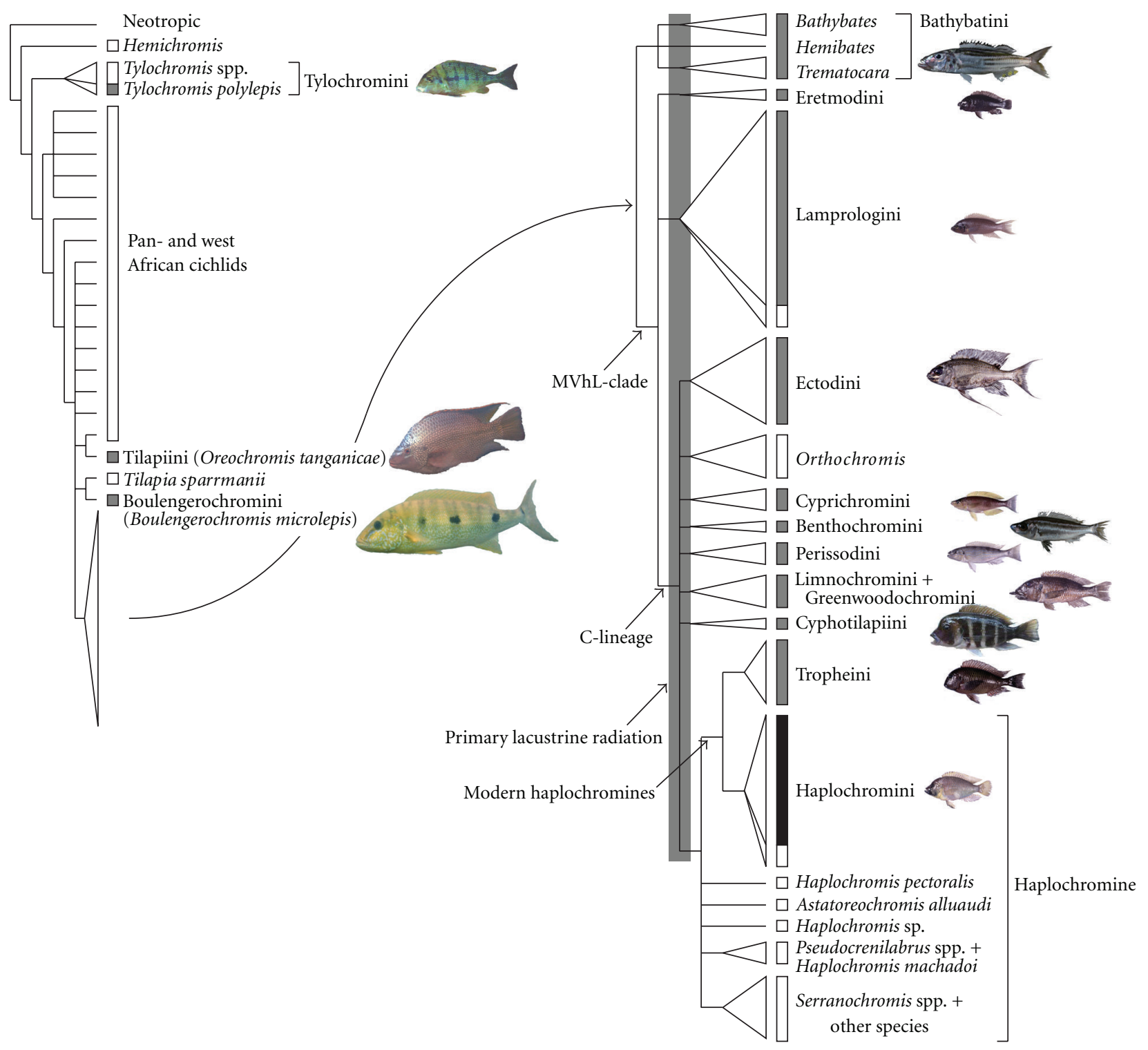

$\square$ Lake Tanganyika

Lakes Victoria and Malawi

$\square$ Rivers and non-ancient lakes

FIGURE 1: Schematic molecular phylogenies of the Lake Tanganyika cichlid assemblage based on combined evidence from several studies: $[24,25]$ for the phylogenetic tree on the left, that shows relationships among major African cichlid lineages, and [26-30] for the phylogenetic tree on the right, that shows a more detailed picture of the intertribal relationships of East African cichlids. Tribe names follow [17]. Tylochromis polylepis and Oreochromis tanganicae colonized the lake only recently and hence established themselves in an already mature adaptive radiation $[25,31]$. In the phylogenetic tree on the right, lineages that underwent radiation are indicated by triangles, with their sizes corresponding to the number of species within the lineage (except for the non-Lake Tanganyika lineages). MVhL-clade was designated by [26], C-lineage by [24], and modern haplochromines by [29]. The Tropheini were shown to be nested within the haplochromine, the largest cichlid tribe that seeded the radiations of the other East African lakes and comprises the majority of North, East, and South African riverine cichlid species $[29,30]$.

smell, and courtship sounds), though distinctions between naturally and sexually selected traits might be not that clear (reviewed in [58]). Many authors have studied morphological traits in Lake Tanganyika cichlids in terms of adaptation. These studies may be classified into four major groups: studies of trophic morphology, body shape, body size, and nervous system.
3.1. Trophic Morphology. Cichlid fishes exhibit a functionally decoupled set of jaws, the oral jaws and the pharyngeal jaws (Figure 2). In particular the pharyngeal jaw is considered a key innovation, representing a key factor for the emergence of a diversity unparalleled among vertebrates [59-61]. The pharyngeal jaw apparatus of cichlid fish is a functionally integrated and highly specialized system and considered to 


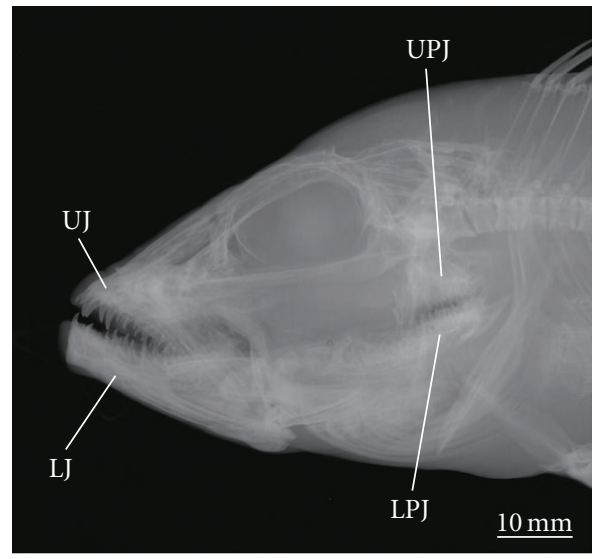

(a)

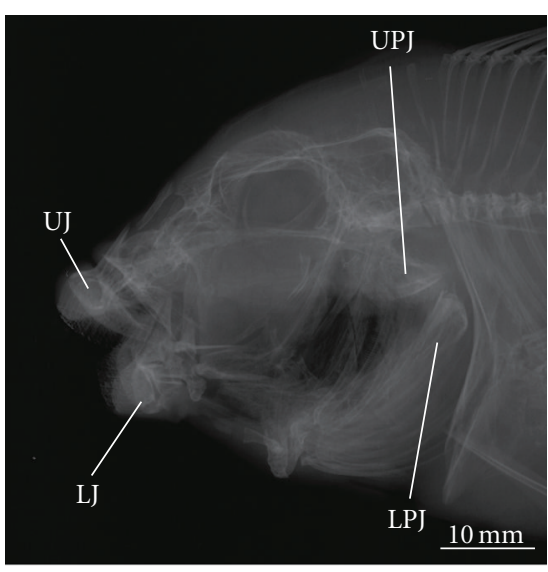

(b)

FIgure 2: X-ray photograph of the head of (a) Lamprologus lemairii (piscivore) and (b) Petrochromis trewavasae (herbivore). LJ and UJ: lower and upper jaws, LPJ and UPJ: lower and upper pharyngeal jaws.

represent a major adaptive complex [59]. Decoupled from the oral jaws, the pharyngeal jaws are used for efficient crushing and processing of food items. Thus, the oral jaws are freed from their dual task of food collection and preparation. Due to this division of functions the development of numerous specializations of food collection and procession mechanisms became possible [59] and minor modifications in oral and pharyngeal jaw structure allow for the utilization of novel food resources within a few generations, such that unexploited ecological niches can be rapidly occupied $[62,63]$. Thus, the specialized pharyngeal jaws in cichlid fish seem to be particularly important for their propensity to rapidly adapt to novel ecological niches, but other trophic morphological features have probably also played key roles for their rapid diversification. Likely, rapid differentiation in trophic specializations results in effective resource partitioning and thus drives the evolution of complex cichlid communities by ecological segregation (e.g., $[64,65])$.

Several studies on Lake Tanganyika cichlids described correlations of the trophic morphology with food habits (oral jaws and teeth [65-69], pharyngeal jaws [59, 69, 70], preorbital region [15, 71], and intestine [72, 73]), suggesting resource-based divergent selection as an important diversifying force in Lake Tanganyika cichlids. In algae feeding species, for example, the shape of jaw teeth differs according to the resources they exploit. Thus, the species of the genus Petrochromis have tricuspid teeth in high density that make a brash-like structure to comb unicellular algae from filamentous algae on rocks, whereas species of Tropheus and some other genera have large bicuspid teeth in the most anterior row that allow to nip and tear off filamentous algae from rocks [66]. Tooth shape-both on oral and pharyngeal jaws - in cichlid fish was shown to respond quickly to selection and change even within the lifetime of a single individual $[74,75]$. Recently, significant advances regarding the developmental pathways and genetic basis leading to different tooth shapes and numbers have been made [76-78].
Further work on this issue will certainly be important to fully understand how inter- and intraspecific differences in tooth shape and numbers emerge as a sometimes quick response to environmental/trophic constraints in species-rich adaptive radiations where species typically occupy a rather narrow ecological niche.

Besides the number and shape of teeth, the shape of the pharyngeal jaws and the oral jaws (or the preorbital region in general) are well known to strongly correlate with diet and were shown to respond quickly to natural selection when new habitats are colonized or when it comes to optimize feeding performance throughout ontogeny. Thus, piscivorous fish were shown to have longer oral jaws than insectivorous and herbivorous fishes [15], and likewise, slender and elongated pharyngeal jaws have been found to be highly correlated with piscivory $[79,80]$. However, recent evidence on the Lake Tanganyika cichlid Lepidiolamprologus elongatus suggests that the mature piscivorous morphotype is refined by a relative widening of the caudal part of the lower pharyngeal jaw, which has been interpreted as prerequisite to the insertion of well-developed musculature and the construction of a powerful lever system which allows for processing large prey fish and relying on exclusive piscivory [70]. The length of the intestine typically varies in the order of piscivores $<$ invertivores $<$ herbivores, and hence diet has been shown to be a good predictor of intestine length at both intra- and inter-specific levels in Lake Tanganyika cichlid fish, indicating that plasticity in intestine length in response to diet is a further important mechanism for driving trophic shifts in adaptive radiations [73].

Correlations between trophic morphology and diet quality were recognized even when accounting for phylogeny in the shape of oral jaw teeth [81] and intestine length [73]. Though divergent natural selection on trophic morphologies leading to rapid morphological change has been shown to be of tremendous importance for the emergence of Lake Tanganyika's astounding cichlid diversity, stabilizing selection seemingly prevents further drastic changes in structures 
relevant for trophic specializations if species are already well adapted to a particular niche within a multispecies assemblage [82]. Balancing selection on trophic traits, on the other hand, may have acted to maintain intrapopulation polymorphism in Lake Tanganyika cichlids [83, 84]. The scaleeating Perissodus microlepis, for example, has morphological dimorphism in the mouth-opening direction to right and left [85]. This deflection of mouth has been shown to be heritable $[86,87]$, though environmental factors can influence the formation of this mouth laterality through development [88]. Several population models have demonstrated that this lateral dimorphism is maintained by negative frequencydependent selection, resulting from interactions between predator and prey species (e.g., $[89,90])$. An empirical study has suggested that disassortative mating between rightmouthed individuals and left-mouthed individuals stabilizes this intrapopulation dimorphism more strongly than only negative frequency-dependent selection acted [91].

In recent years, significant advances have been made towards the understanding of the genetic basis of differences in the cichlids' jaw morphologies [92-94]. Yet, further work on the genetic determination of jaw morphologies, the genetic basis of other diet-related traits (e.g., pharyngeal bone and intestine), and studies on the efficiency of particular trophic morphologies in feeding, processing, and digesting food items are required to gain further insights into the mechanisms underlying the rapid generation of a multitude of trophic types as adaptation to particular resources in Lake Tanganyika cichlid fishes.

The trophic specialization of the pharyngeal jaws may also lead to reproductive isolation between species via mate choice. Cichlid fish produce sound during male courtship display $[95,96]$, and this sound appears to be produced by stridulation of the pharyngeal jaws [97]. Courtship sounds have been shown to differ among closely related species of Lake Malawi cichlids $[96,98]$. Thus, if females use male courtship sound as a cue for mate choice, inter-specific differences in sound may possibly cause assortative mating, and consequently reproductive isolation [95, 97]. The Lake Tanganyika cichlids are highly diverse in pharyngeal jaw morphology, and thus, mate choice based on courtship sounds might represent an additional mode of diversification or prevent heterospecific pairings between already differentiated closely related species, a hypothesis that calls for further detailed investigations.

3.2. Body Shape. The influence of phylogeny on the evolution of body shape is small in the Lake Tanganyika cichlids, and it appears that body shape evolution is strongly affected by feeding habits [18]. Piscivorous fish, for example, typically have a much larger head and benthivorous fish tend to have a slender body [18]. Thus, body shape is not independent from trophic morphology [99]. The body shapes are generally associated with swimming modes in fish (e.g., [100-102]), suggesting that the divergent body shapes of the Lake Tanganyika cichlids also relate to other ecological factors, such as the efficiency of escaping from predators.

In some maternally mouth-brooding species, the size and shape of the head differ between sexes. This sexual dimorphism in head size and shape appears to be related to a larger buccal cavity in females [103, 104], suggesting that the evolution of body shape is partly associated with reproductive ecology. In the Tropheus moorii species complex, differences in the orientation of the mouth and the head profile have been observed among populations, despite a lack of obvious differences in food preferences, mating, and breeding behaviour [104, 105], indicating that these observed difference in body shape might be due to random genetic drift. Genetic drift can evolve phenotypes without adaptation, and perhaps it can take populations through adaptive valleys and into the domains of new adaptive peaks (peak shifts by drift, reviewed in [19]). Nevertheless, the Lake Tanganyika cichlid species have to establish themselves in a densely packed multispecies community. Consequently intraspecific morphological variation is typically rather low in the natural environment due to inter-specific competition and narrow ecological niches confining the morphospace occupied by a single species. If environmental conditions change, the phenotype might rapidly adapt to the new environment. This phenomenon has been recently shown by comparing morphologies of individuals of four wild populations of the Tropheus moorii species complex with their pond-raised $\mathrm{F}_{1}$ offspring [106]. The extent of morphological change between wild and pond-raised $F_{1}$ fish was 2.4 times larger than the pairwise population differences, and all four populations exhibited the same overall trend in morphological change.

In the Lake Tanganyika cichlids, the diversity of body shape may at least partly be associated with adaptive radiation of the fish through resource partitioning, assortative mating, low hybrid fitness, and/or other mechanisms. However, nothing is known about the genetic basis of body shapes and also detailed studies on the efficiency of particular body shapes in feeding and swimming are lacking, thus opening a huge field of research for the future.

3.3. Body Size. Body size is one of the simplest characters that show diversity between species. Body size evolution results from a balance between selection favouring large body size and selection favouring small body size (e.g., $[107,108])$. While it is widely agreed that fecundity selection for females and sexual selection for males are the major evolutionary forces that favour larger body size in most sexual animals, counterbalancing selection favouring small body size is often masked by the good condition of the larger individuals and is therefore less obvious [108]. In the Lake Tanganyika cichlid fish, body size greatly varies from 42 to $650 \mathrm{~mm}$ in standard length (the smallest species is the shell-brooder Neolamprologus multifasciatus, and the largest species is the substrate brooder Boulengerochromis microlepis [34]). The effect of environmental constraints on body size has been studied in Telmatochromis temporalis. This species comprises dwarf and normal morphs, and the two morphs were shown to have evolved through divergent natural selection, in which the small body size of the dwarf morph was a result of adaptation to utilize empty gastropod-shells as shelters $[109,110]$. The trait utility of body size has been examined in another shell-brooder, Lamprologus callipterus, that shows the most 
extreme male-biased sexual size dimorphism among animals (males > 12 times heavier than females [111]). Males of this species collect empty gastropod-shells to build up their nests. This behaviour is unique among the Lake Tanganyika cichlids. Experimental and theoretical tests suggested that the large male size of this species was determined by the ability to carry empty shells [112] and intersexual selection [113], and experimental tests suggested that the female size was limited by the ability to spawn eggs inside the shells [112].

Size-assortative mating has been reported in a wide range of animal taxa (e.g., planarians [114], snails [115], gammarus [116], insects [117-119], fishes [120, 121], toads [122], snakes [123], lizards [124], mammals [125], and birds [126]) and can cause reproductive isolation between species or morphs as byproducts of differences in body size [127129]. In the Lake Tanganyika cichlid fish, divergent natural selection on body size might have been contributed to at least a part of explosive radiation of this species flock through assortative mating, and further, other various mechanisms such as low hybrid fitness and resource partitioning. Further work on intrinsic and extrinsic factors that affect the body size may give deep insights into the mechanisms underlying the adaptive radiation of these fish.

3.4. Nervous System. Some studies have described correlations between nervous system and ecology. Huber and colleagues [130] and Pollen and colleagues [131] demonstrated that the relative development of various brain structures relates to habitat, social behaviour, resources, and environment. Thus, in the tribe Ectodini for example, telencephalon, that appears to be involved in a variety of tasks, such as processing olfactory, visual and gustatory stimuli, and in learning, agonistic and courtship behaviours [130], was larger, and hypothalamus, that appears to have integrative functions relating to feeding, aggression, reproduction, and vision [130], was smaller in monogamous species compared to polygamous species. These studies suggest that selection or drift can act independently on different brain regions. Gonzalez-Voyer and colleagues [57] showed that female brain size correlated with brood care type and diet type and that male brain size correlated with diet type only, suggesting that more complex diet selection and larger burden on brood care may demand larger brain size. Sylvester and colleagues [132] showed that an alternative SNP in irx1b potentially causes differences in the relative size of the telencephalon versus the thalamus between rock-dwelling and sand-dwelling Lake Malawi cichlids. Although it is not at all obvious how an increase in the size of brain would give rise to functional differences (e.g., increased cognitive abilities) [133], the brain morphology may have played important roles in adaptive radiation of the Lake Tanganyika cichlids.

3.5. Other Morphologies. We reviewed a trophic morphology, body shape, body size, and nervous system, morphological traits that might be causally involved in the adaptive radiation of the Lake Tanganyika cichlids. However, these fish are highly diverse also in other morphological traits. The diversity of these other traits may be a result of adaptation to various environments, genetic drift, or phenotypic plasticity during development. Unfortunately, hardly anything is known about function and genetic basis of these traits. For example, the infraorbitals (a series of bones surrounding the lower half of the eye) were shown to vary considerably in shape among the Lake Tanganyika cichlids (Figure 3) [134]. However, it is still unknown what exactly caused the observed inter-specific differences in this morphological structure, though it has been argued that infraorbitals have the function to regulate the movement of jaws in relation to some other bones [15], and that the number and size of sensory pores on these bones may be associated with the noise sensitivity [135].

Some morphological characters differ at various taxonomic levels, reflecting difference in the relative time of morphological divergence. For example, the shape of infraorbitals tends to differ between tribes, suggesting that this morphology diverged during the initial radiation. The body shape and the shape of oral jaw teeth, on the other hand, tend to differ at lower taxonomic levels, such as between genera and between species, suggesting that the divergence of these morphologies reflect later evolutionary events.

\section{Ontogenetic Changes in Morphology: A Largely Neglected Issue in Lake Tanganyika Cichlids}

Studies on adaptation and natural selection typically focus on traits in adult organisms, but high mortality among juveniles indicates that - in addition to predation pressurestrong selection pressure, competition avoidance, and resource partitioning are presumably important already early on in life (e.g., [136]). Thus, individuals do not only have to compete for resources against heterospecific individuals but also against conspecifics. For species that comprise a number of cooccurring size-classes (many invertebrates, fish, amphibians, and reptiles) niche separation by body size differences poses a complex problem since the smallest sizeclasses of one species often overlap with the largest of another [137].

Since resource utilization abilities and predation risk are generally related to body size, many species undergo-sometimes dramatic-ontogenetic shifts in habitat use and/or food choice [138]. Thus, among fish, ontogenetic changes in resource use are nearly universal and size-related shifts in food choice have been documented in numerous species, typically with positive correlations between food size and body size (e.g., [139-145]). These ontogenetic shifts in resource use might vastly complicate species interactions with important consequences for community dynamics, in particular in multispecies communities [138]. If small and large species coexist, the most critical feature of this interaction is not how adults of these two species interact, but how the larger species is able to recruit through juvenile stages that are identical to the size ranges present in the smaller species. Interactions of this sort might form bottlenecks in recruitment to the species [146], and thus adaptive finetuning is particularly important in juvenile stages, especially 


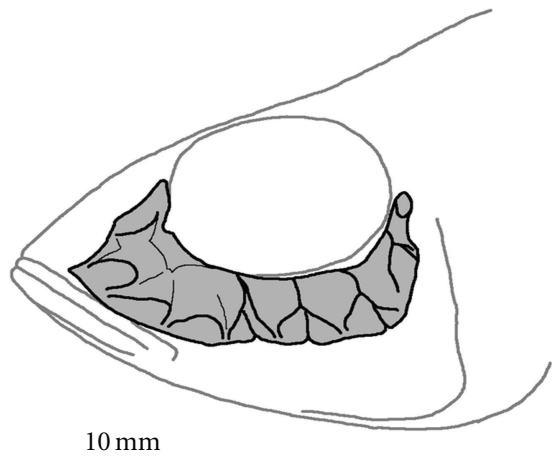

(a)

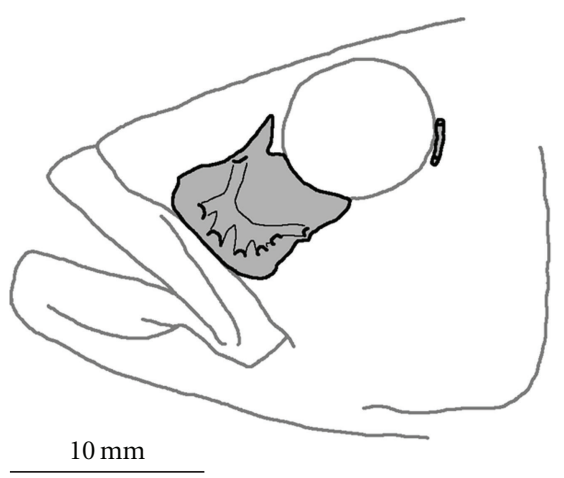

(b)

Figure 3: Infraorbitals of (a) Trematocara unimaculatum (Bathybatini) and (b) Lepidiolamprologus profundicola (Lamprologini). The infraorbitals vary in the number of bones, the degree of development of bones, and the numbers and size of sensory pores on the bones.

in regions/periods where/when resources are limited. Ontogenetic niche shifts aid in maximizing fitness by reducing competition with conspecifics via resource segregation [138], by minimizing predation risk through habitat shifts [147], and by maximizing growth through dietary shifts [148]. These ontogenetic shifts in resource use might be rather abrupt and are often correlated with discrete growth periods in the life history (e.g., $[149,150])$. For many primarily piscivorous fishes the transition to piscivory is a crucial ontogenetic niche shift [151]. Typically, highly specialized piscivores are not particularly well adapted to feeding on zooplankton and benthic invertebrates, which are their predominant prey early in life $[138,151]$, and delayed shifts to piscivory can result in slow growth and increased mortality, in particular when competing for resources with specialist planktivorous species $[138,151,152]$. The switch to piscivory often initiates an increase in growth rate, translating into larger body size and greater survival-larger individuals are typically less vulnerable to predation and are better adapted to survive periods of starvation-throughout life for specialized piscivores $[151,152]$. Transition dates might vary considerably among species (e.g., [151]). Several factors, for example, species-specific differences in the allometry of trophic structures, hatching time and size at hatching, have been proposed to at least partially explain these inter-specific differences in the timing of the switch to piscivory $[151,153]$. Although there is a considerable amount of studies relating dietary shifts to ontogenetic changes of overall body shape in fishes (e.g., [139-141, 144, 145]), studies that directly relate ontogenetic changes in diet and growth patterns of the trophic apparatus are scarce (e.g., [142]). Whereas isometric growth of the lower pharyngeal jaw was reported for the Lake Tanganyika cichlid Lamprologus ornatipinnis [69], a species that predominantly feeds on invertebrates and thus does not experience a drastic shift in feeding habits throughout ontogeny, Hellig and colleagues [70] showed that an allometric change in ontogenetic lower pharyngeal jaw development of Lepidiolamprologus elongatus, a top predator in the shallow rocky habitat of Lake Tanganyika, coincides with the dietary shift to exclusive piscivory (Figure 4). This observation might indicate that distinct allometry is correlated with strong specialization, but it remains to be tested whether this is a general phenomenon in trophic specialists, what is the genetic basis of such morphological changes, and to what extent differential gene expression producing differences in morphology contributes to the astounding diversity of cichlid fishes in Lake Tanganyika.

\section{Conclusions}

Along with the Darwin's finches from the Galápagos Islands (e.g., [158]) and the Hawaiian silverswords (e.g., [159]) the East African cichlid species flocks represent well-established model systems for the study of adaptive radiation. Numerous morphological studies on the Lake Tanganyika cichlid species flock have greatly contributed to the ever-increasing knowledge on the evolutionary pathways and mechanisms generating tremendous diversity within a short period of time. Rapid changes in particular morphological traits allow for the rapid adaptation of cichlid fish to novel resources. Thus, such adaptive phenotypes would have played important roles during adaptive radiation. The Lake Tanganyika cichlids are highly diverse in their morphology, and many morphological traits appear to have been concerned with adaptive radiation. However, the knowledge about adaptive phenotypes is still poor. Clearly, more studies are required to reveal the mechanisms of adaptive radiation of these fish, but recent methodological advances, in particular in the field of geometric morphometrics, appear promising for answering a wide variety of evolutionary questions and even allow for addressing population-level questions regarding (adaptive) shape changes (reviewed in [160]).

In the present review, we only surveyed morphological studies. However, only the integration of evidence from various fields of research will significantly advance our understanding of the evolutionary mechanisms underlying the adaptive radiation(s) of (Lake Tanganyika) cichlid fish. For example, disruptive sexual selection on male colouration has been shown to drive speciation in some Lake Malawi and Victoria cichlids (e.g., [161-163]), and olfactory cues are important for mate choice in some Lake Malawi cichlids [164]. Thus, female choice for male nuptial colour and 


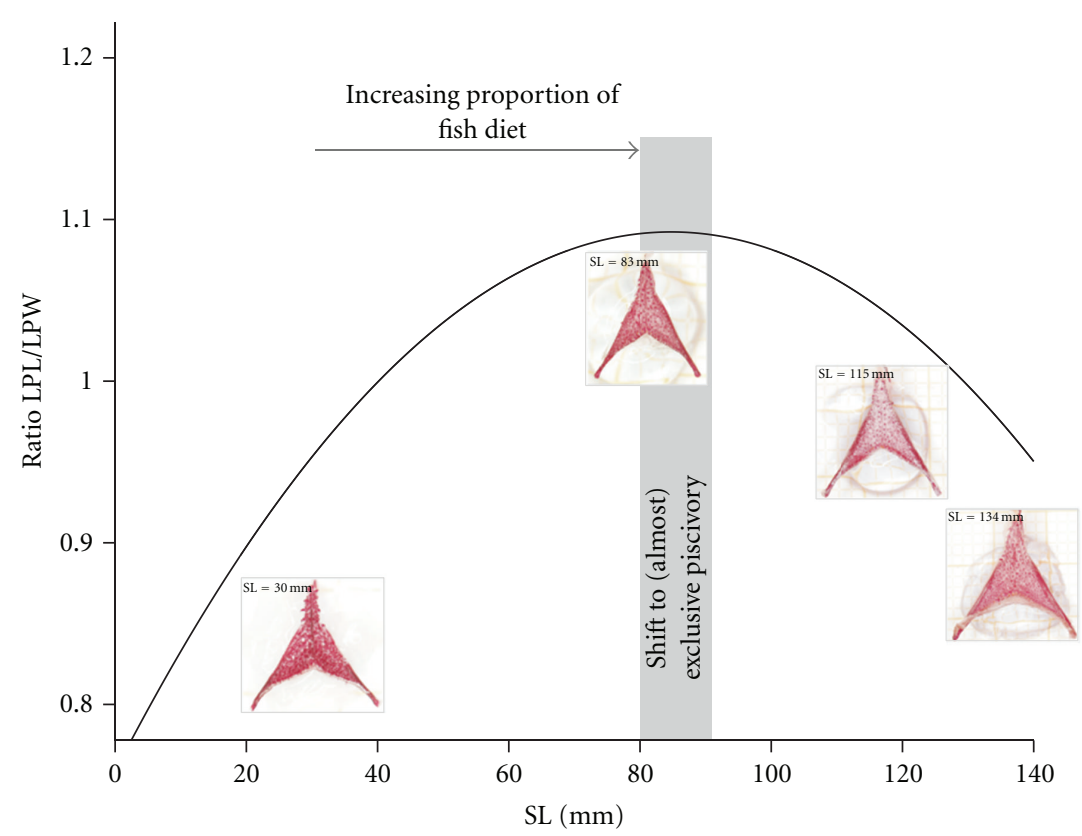

FIGURE 4: Schematic depiction of the allometric shape change of the lower pharyngeal jaw of Lepidiolamprologus elongatus, a diurnal top predator in Lake Tanganyika's shallow rocky habitat (modified from [70]). Note that the allometric shape change coincides with the shift to (almost) exclusive piscivory (data on feeding habits from [154-157]. The lower pharyngeal jaws of representatives of four distinct size classes are also shown to highlight the overall allometric shape change. SL, standard length; LPL, length of lower pharyngeal jaw; LPW, width of lower pharyngeal jaw.

olfactory signals may also have played (and still play) important roles in at least a part of the explosive radiation of the Lake Tanganyika cichlid species flock [58]. Indeed, more than $10 \%$ of Lake Tanganyika's cichlid species (e.g., Cyprichromini, Benthochromini, and some species of Ectodini, Tropheini, and Bathybatini) exhibit obvious sexual colour dimorphism [34]. However, at present there is no clear evidence for sexual selection based on body coloration being of great importance for driving rapid diversification in Lake Tanganyika's cichlid species flock. However, body coloration might serve as cue for species/mate recognition and prevent inter-specific or intermorph gene flow in case of secondary contact, be it human induced or due to lake level fluctuations, exemplified by evidence for colour assortative mating among originally allopatrically distributed colour morphs of Tropheus moorii [165-167]. Thus, allopatrically evolved mate choice cues serve as prezygotic isolation mechanisms preventing cichlid species/morphs from hybridization in the case of secondary contact.

Recent paleolimnological and geological studies have shed light on the dynamics of past water level fluctuations that act as "species pumps" by recurrent fragmentation and secondary admixis of populations [168] in the East African Great Lakes [169-171]. Ecological studies provide insights into the degree of intra- and inter-specific interactions (e.g., [172-179]), and the recent developments in sequencing techniques allow for the generation of huge amounts of sequence data at comparatively low costs provide exciting new possibilities to investigate phylogenetic relationships among taxa, population genetic structure, and the genetic basis and regulation of particular traits. At present, we are still far away from completely understanding what has driven and still drives the rapid diversification in East African cichlid species flocks, but recent advances in various fields of research hold a promising future for researchers.

\section{Acknowledgments}

This study was partly supported by Grants-in-Aid for Young Scientists (no. 20770065) to T. Takahashi, and Global COE Program (A06) to Kyoto University.

\section{References}

[1] J. Snoeks, "How well known is the ichthyodiversity of the large East African lakes?" Advances in Ecological Research, vol. 31, pp. 17-38, 2000.

[2] G. F. Turner, O. Seehausen, M. E. Knight, C. J. Allender, and R. L. Robinson, "How many species of cichlid fishes are there in African lakes?" Molecular Ecology, vol. 10, no. 3, pp. 793806, 2001.

[3] G. F. Turner, "Adaptive radiation of cichlid fish," Current Biology, vol. 17, no. 19, pp. R827-R831, 2007.

[4] G. Fryer and T. D. Iles, The Cichlid Fishes of the Great Lakes of Africa: Their Biology and Evolution, Oliver \& Boyd, Edinburgh, UK, 1972.

[5] A. Meyer, "Phylogenetic relationships and evolutionary processes in East African cichlid fishes," Trends in Ecology and Evolution, vol. 8, no. 8, pp. 279-284, 1993. 
[6] I. Kornfield and P. F. Smith, "African cichlid fishes: model systems for evolutionary biology," Annual Review of Ecology and Systematics, vol. 31, pp. 163-196, 2000.

[7] T. D. Kocher, "Adaptive evolution and explosive speciation: the cichlid fish model," Nature Reviews Genetics, vol. 5, no. 4, pp. 288-298, 2004.

[8] W. Salzburger and A. Meyer, "The species flocks of East African cichlid fishes: recent advances in molecular phylogenetics and population genetics," Naturwissenschaften, vol. 91, no. 6, pp. 277-290, 2004.

[9] O. Seehausen, "African cichlid fish: a model system in adaptive radiation research," Proceedings of the Royal Society B, vol. 273, no. 1597, pp. 1987-1998, 2006.

[10] S. Koblmüller, K. M. Sefc, and C. Sturmbauer, "The Lake Tanganyika cichlid species assemblage: recent advances in molecular phylogenetics," Hydrobiologia, vol. 615, no. 1, pp. 5-20, 2008.

[11] A. S. Cohen, M. J. Soreghan, and C. A. Scholz, "Estimating the age of formation of lakes: an example from Lake Tanganyika, East African Rift system," Geology, vol. 21, no. 6, pp. 511-514, 1993.

[12] P. H. Greenwood, "African cichlids and evolutionary theories," in Evolution of Fish Species Flocks, A. A. Echelle and I. Kornfield, Eds., pp. 141-154, University of Maine at Orono Press, Orono, Me, USA, 1984.

[13] P. Chakrabarty, "Testing conjectures about morphological diversity in cichlids of Lakes Malawi and Tanganyika," Copeia, no. 2, pp. 359-373, 2005.

[14] K. A. Young, J. Snoeks, and O. Seehausen, "Morphological diversity and the roles of contingency, chance and determinism in African cichlid radiations," PLoS One, vol. 4, no. 3, Article ID e4740, 2009.

[15] W. J. Cooper, K. Parsons, A. McIntyre, B. Kern, A. McGeeMoore, and R. C. Albertson, "Bentho-pelagic divergence of cichlid feeding architecture was prodigious and consistent during multiple adaptive radiations within African RiftLakes," PLoS One, vol. 5, no. 3, Article ID e9551, 2010.

[16] M. Poll, "Classification des Cichlidae du lac Tanganika. Tribus, genres et espèces," Académie Royale de Belgique Mémoires de la Classe des Sciences, Series 2, vol. 45, no. 2, pp. 1-163, 1986.

[17] T. Takahashi, "Systematics of Tanganyikan cichlid fishes (Teleostei: Perciformes)," Ichthyological Research, vol. 50, no. 4, pp. 367-382, 2003.

[18] C. Clabaut, P. M. E. Bunje, W. Salzburger, and A. Meyer, "Geometric morphometric analyses provide evidence for the adaptive character of the Tanganyikan cichlid fish radiations," Evolution, vol. 61, no. 3, pp. 560-578, 2007.

[19] D. Schluter, The Ecology of Adaptive Radiation, Oxford University Press, Oxford, UK, 2000.

[20] D. Schluter, "Ecology and the origin of species," Trends in Ecology and Evolution, vol. 16, no. 7, pp. 372-380, 2001.

[21] H. D. Rundle and P. Nosil, "Ecological speciation," Ecology Letters, vol. 8, no. 3, pp. 336-352, 2005.

[22] D. J. Futuyma and G. Moreno, "The evolution of ecological specialization," Annual Review of Ecology and Systematics, vol. 19, pp. 207-233, 1988.

[23] T. Dayan and D. Simberloff, "Ecological and communitywide character displacement: the next generation," Ecology Letters, vol. 8, no. 8, pp. 875-894, 2005.

[24] C. Clabaut, W. Salzburger, and A. Meyer, "Comparative phylogenetic analyses of the adaptive radiation of Lake Tanganyika cichlid fish: Nuclear sequences are less homoplasious but also less informative than mitochondrial DNA," Journal of Molecular Evolution, vol. 61, no. 5, pp. 666-681, 2005.

[25] V. Klett and A. Meyer, "What, if anything, is a Tilapia?mitochondrial ND2 phylogeny of tilapiines and the evolution of parental care systems in the African cichlid fishes," Molecular Biology and Evolution, vol. 19, no. 6, pp. 865-883, 2002.

[26] K. Takahashi, Y. Terai, M. Nishida, and N. Okada, "Phylogenetic relationships and ancient incomplete lineage sorting among cichlid fishes in lake Tanganyika as revealed by analysis of the insertion of retroposons," Molecular Biology and Evolution, vol. 18, no. 11, pp. 2057-2066, 2001.

[27] W. Salzburger, A. Meyer, S. Baric, E. Verheyen, and C. Sturmbauer, "Phylogeny of the Lake Tanganyika cichlid species flock and its relationship to the Central and East African haplochromine cichlid fish faunas," Systematic Biology, vol. 51, no. 1, pp. 113-135, 2002.

[28] S. Koblmüller, N. Duftner, C. Katongo, H. Phiri, and C. Sturmbauer, "Ancient divergence in bathypelagic Lake Tanganyika deepwater cichlids: mitochondrial phylogeny of the tribe Bathybatini," Journal of Molecular Evolution, vol. 60, no. 3, pp. 297-314, 2005.

[29] W. Salzburger, T. Mack, E. Verheyen, and A. Meyer, "Out of Tanganyika: genesis, explosive speciation, key-innovations and phylogeography of the haplochromine cichlid fishes," BMC Evolutionary Biology, vol. 5, article 17, 2005.

[30] S. Koblmüller, U. K. Schliewen, N. Duftner, K. M. Sefc, C. Katongo, and C. Sturmbauer, "Age and spread of the haplochromine cichlid fishes in Africa," Molecular Phylogenetics and Evolution, vol. 49, no. 1, pp. 153-169, 2008.

[31] M. Koch, S. Koblmüller, K. M. Sefc, N. Duftner, C. Katongo, and C. Sturmbauer, "Evolutionary history of the endemic Lake Tanganyika cichlid fish Tylochromis polylepis: a recent intruder to a mature adaptive radiation," Journal of Zoological Systematics and Evolutionary Research, vol. 45, no. 1, pp. 64$71,2007$.

[32] M. Nishida, "Lake Tanganyika as an evolutionary reservoir of old lineages of East African cichlid fishes: Inferences from allozyme data," Experientia, vol. 47, no. 9, pp. 974-979, 1991.

[33] Y. Terai, K. Takahashi, M. Nishida, T. Sato, and N. Okada, "Using SINEs to probe ancient explosive speciation: "Hidden" radiation of African cichlids?" Molecular Biology and Evolution, vol. 20, no. 6, pp. 924-930, 2003.

[34] M. Poll, "“Poissons Cichlidae," Résultats Scientifiques, Exploration Hydrobiologique du Lac Tanganika (1946-1947)," Institut Royal des Sciences Naturelles de Belgique, vol. 3, no. 5B, pp. 1-619, 1956.

[35] R. C. Schelly and M. L. J. Stiassny, "Revision of the Congo River Lamprologus Schilthuis, 1891 (Teleostei: Cichlidae), with descriptions of two new species," American Museum Novitates, vol. 3451, pp. 1-40, 2004.

[36] R. Schelly, M. L. J. Stiassny, and L. Seegers, "Neolamprologus devosi sp. n., a new riverine lamprologine cichlid (Teleostei: Cichlidae) from the lower Malagarasi River, Tanzania," Zootaxa, vol. 373, pp. 1-11, 2003.

[37] C. Sturmbauer, E. Verheyen, and A. Meyer, "Mitochondrial phylogeny of the lamprologini, the major substrate spawning lineage of cichild fishes from Lake Tanganyika in Eastern Africa," Molecular Biology and Evolution, vol. 11, no. 4, pp. 691-703, 1994.

[38] C. Sturmbauer, W. Salzburger, N. Duftner, R. Schelly, and S. Koblmüller, "Evolutionary history of the Lake Tanganyika cichlid tribe Lamprologini (Teleostei: Perciformes) derived from mitochondrial and nuclear DNA data," Molecular Phylogenetics and Evolution, vol. 57, no. 1, pp. 266-284, 2010. 
[39] M. J. Genner, O. Seehausen, D. H. Lunt et al., "Age of cichlids: new dates for ancient lake fish radiations," Molecular Biology and Evolution, vol. 24, no. 5, pp. 1269-1282, 2007.

[40] J. Schwarzer, B. Misof, D. Tautz, and U. K. Schliewen, "The root of the East African cichlid radiations," BMC Evolutionary Biology, vol. 9, no. 1, article 186, 2009.

[41] J. J. Tiercelin and A. Mondeguer, "The geology of the Tanganyika trough," in Lake Tanganyika and Its Life, G. W. Coulter, Ed., pp. 7-48, Oxford University Press, New York, NY, USA, 1991.

[42] A. S. Cohen, K. E. Lezzar, J. J. Tiercelin A, and M. Soreghan, "New palaeogeographic and lake-level reconstructions of Lake Tanganyika: implications for tectonic, climatic and biological evolution in a rift lake," Basin Research, vol. 9, no. 2, pp. 107-132, 1997.

[43] D. A. Joyce, D. H. Lunt, R. Bills et al., "An extant cichlid fish radiation emerged in an extinct Pleistocene lake," Nature, vol. 435, no. 7038, pp. 90-95, 2005.

[44] C. Sturmbauer, U. Hainz, S. Baric, E. Verheyen, and W. Salzburger, "Evolution of the tribe Tropheini from Lake Tanganyika: synchronized explosive speciation producing multiple evolutionary parallelism," Hydrobiologia, vol. 500, pp. 51-64, 2003.

[45] S. Koblmüller, W. Salzburger, and C. Sturmbauer, "Evolutionary relationships in the sand-dwelling cichlid lineage of Lake Tanganyika suggest multiple colonization of rocky habitats and convergent origin of biparental mouthbrooding," Journal of Molecular Evolution, vol. 58, no. 1, pp. 79-96, 2004.

[46] N. Duftner, S. Koblmüller, and C. Sturmbauer, "Evolutionary relationships of the Limnochromini, a tribe of benthic deepwater cichlid fish endemic to Lake Tanganyika, East Africa," Journal of Molecular Evolution, vol. 60, no. 3, pp. 277289, 2005.

[47] W. Salzburger, S. Baric, and C. Sturmbauer, "Speciation via introgressive hybridization in East African cichlids?" Molecular Ecology, vol. 11, no. 3, pp. 619-625, 2002.

[48] R. Schelly, W. Salzburger, S. Koblmüller, N. Duftner, and C. Sturmbauer, "Phylogenetic relationships of the lamprologine cichlid genus Lepidiolamprologus (Teleostei: Perciformes) based on mitochondrial and nuclear sequences, suggesting introgressive hybridization," Molecular Phylogenetics and Evolution, vol. 38, no. 2, pp. 426-438, 2006.

[49] S. Koblmüller, N. Duftner, K. M. Sefc et al., "Reticulate phylogeny of gastropod-shell-breeding cichlids from Lake Tanganyika - the result of repeated introgressive hybridization," BMC Evolutionary Biology, vol. 7, article 7, 2007.

[50] S. Koblmüller, B. Egger, C. Sturmbauer, and K. M. Sefc, "Evolutionary history of Lake Tanganyika's scale-eating cichlid fishes," Molecular Phylogenetics and Evolution, vol. 44, no. 3, pp. 1295-1305, 2007.

[51] R. Takahashi, K. Watanabe, M. Nishida, and M. Hori, "Evolution of feeding specialization in Tanganyikan scale-eating cichlids: a molecular phylogenetic approach," BMC Evolutionary Biology, vol. 7, no. 1, article 195, 2007.

[52] B. Nevado, S. KoblmÜller, C. Sturmbauer, J. Snoeks, J. Usano-Alemany, and E. Verheyen, "Complete mitochondrial DNA replacement in a Lake Tanganyika cichlid fish," Molecular Ecology, vol. 18, no. 20, pp. 4240-4255, 2009.

[53] S. Koblmüller, B. Egger, C. Sturmbauer, and K. M. Sefc, "Rapid radiation, ancient incomplete lineage sorting and ancient hybridization in the endemic Lake Tanganyika cichlid tribe Tropheini," Molecular Phylogenetics and Evolution, vol. 55, no. 1, pp. 318-334, 2010.
[54] N. Kolm, N. B. Goodwin, S. Balshine, and J. D. Reynolds, "Life history evolution in cichlids 2: directional evolution of the trade-off between egg number and egg size," Journal of Evolutionary Biology, vol. 19, no. 1, pp. 76-84, 2006.

[55] F. Duponchelle, E. Paradis, A. J. Ribbink, and G. F. Turner, "Parallel life history evolution in mouthbrooding cichlids from the African Great Lakes," Proceedings of the National Academy of Sciences of the United States of America, vol. 105, no. 40, pp. 15475-15480, 2008.

[56] A. Gonzalez-Voyer, J. L. Fitzpatrick, and N. Kolm, "Sexual selection determines parental care patterns in cichlid fishes," Evolution, vol. 62, no. 8, pp. 2015-2026, 2008.

[57] A. Gonzalez-Voyer, S. Winberg, and N. Kolm, "Social fishes and single mothers: brain evolution in African cichlids," Proceedings of the Royal Society B, vol. 276, no. 1654, pp. 161167, 2009.

[58] W. Salzburger, "The interaction of sexually and naturally selected traits in the adaptive radiations of cichlid fishes," Molecular Ecology, vol. 18, no. 2, pp. 169-185, 2009.

[59] K. F. Liem, "Evolutionary strategies and morphological innovations: cichlid pharyngeal jaws," Systematic Zoology, vol. 22, no. 4, pp. 425-441, 1973.

[60] F. Galis and J. A. J. Metz, "Why are there so many cichlid species?" Trends in Ecology and Evolution, vol. 13, no. 1, pp. $1-2,1998$.

[61] C. D. Hulsey, F. J. García De León, and R. Rodiles-Hernández, "Micro- and macroevolutionary decoupling of cichlid jaws: a test of liem's key innovation hypothesis," Evolution, vol. 60, no. 10, pp. 2096-2109, 2006.

[62] M. L. J. Stiassny, "Phylogenetic interrelationships of the family Cichlidae: an overview," in Cichlid Fishes, Behaviour, Ecology and Evolution, M. H. A. Keenleyside, Ed., pp. 1-35, Chapman \& Hall, London, UK, 1991.

[63] C. Sturmbauer, "Explosive speciation in cichlid fishes of the African Great Lakes: a dynamic model of adaptive radiation," Journal of Fish Biology, vol. 53, pp. 18-36, 1998.

[64] K. R. McKaye and A. Marsh, "Food switching by two specialized algae-scraping cichlid fishes in Lake Malawi, Africa," Oecologia, vol. 56, no. 2-3, pp. 245-248, 1983.

[65] M. Barluenga, K. N. Stölting, W. Salzburger, M. Muschick, and A. Meyer, "Sympatric speciation in Nicaraguan crater lake cichlid fish,” Nature, vol. 439, no. 7077, pp. 719-723, 2006.

[66] K. Yamaoka, "Feeding behaviour and dental morphology of algae scraping cichlids (Pisces: Teleostei) in Lake Tanganyika," African Study Monographs, vol. 4, pp. 77-89, 1983.

[67] K. Yamaoka, "Ecomorphology of feeding in 'goby-like' cichlid fishes in Lake Tanganyika," Physiology and Ecology Japan, vol. 23, pp. 17-29, 1986.

[68] K. Yamaoka, "Comparative osteology of the jaw of algalfeeding cichlids (Pisces, Teleostei) from Lake Tanganyika," Reports of the Usa Marine Biological Institute, Kochi University, vol. 9, pp. 87-137, 1987.

[69] A. K. Gordon and I. R. Bills, "Aspects of the feeding and reproductive biology of the Lake Tanganyikan cichlid, Lamprologus ornatipinnis (Pisces, Cichlidae)," Environmental Biology of Fishes, vol. 55, no. 4, pp. 431-441, 1999.

[70] C. J. Hellig, M. Kerschbaumer, K. M. Sefc, and S. Koblmüller, "Allometric shape change of the lower pharyngeal jaw correlates with a dietary shift to piscivory in a cichlid fish," Naturwissenschaften, vol. 97, no. 7, pp. 663-672, 2010.

[71] K. J. Parsons, W. J. Cooper, and R. C. Albertson, "Modularity of the oral jaws is linked to repeated changes in the 
craniofacial shape of African cichlids," International Journal of Evolutionary Biology, vol. 2011, Article ID 641501, 2011.

[72] K. Yamaoka, "Intestinal coiling pattern in the epilithic algalfeeding cichlids (Pisces, Teleostei) of Lake Tanganyika, and its phylogenetic significance," Zoological Journal of the Linnean Society, vol. 84, no. 3, pp. 235-261, 1985.

[73] C. E. Wagner, P. B. McIntyre, K. S. Buels, D. M. Gilbert, and E. Michel, "Diet predicts intestine length in Lake Tanganyika's cichlid fishes," Functional Ecology, vol. 23, no. 6, pp. 11221131, 2009.

[74] A. Meyer, "Phenotypic plasticity and heterochrony in Cichlasoma managuense (Pieces, Cichlidae) and their implications for speciation in cichlid fishes," Evolution, vol. 41, pp. 1357$1369,1987$.

[75] A. Huysseune, "Phenotypic plasticity in the lower pharyngeal jaw dentition of Astatoreochromis alluaudi (Teleostei: Cichlidae)," Archives of Oral Biology, vol. 40, no. 11, pp. 1005-1014, 1995.

[76] J. T. Streelman, J. F. Webb, R. C. Albertson, and T. D. Kocher, "The cusp of evolution and development: a model of cichlid tooth shape diversity," Evolution and Development, vol. 5, no. 6, pp. 600-608, 2003.

[77] E. Vandervennet, K. Wautier, E. Verheyen, and A. Huysseune, "From conical to spatulate: intra- and interspecific changes in tooth shape in closely related cichlids (Teleostei; Cichlidae: Eretmodini)," Journal of Morphology, vol. 267, no. 4, pp. 516$525,2006$.

[78] G. J. Fraser, C. D. Hulsey, R. F. Bloomquist, K. Uyesugi, N. R. Manley, and J. T. Streelman, "An ancient gene network is co-opted for teeth on old and new jaws.," PLoS Biology, vol. 7, no. 2, article e1000031, 2009.

[79] C. D. N. Barel, M. J. P. Van Oijen, F. Witte, and E. L. M. WitteMaas, "An introduction to the taxonomy and morphology of the haplochromine Cichlidae from Lake Victoria. A manual to Greenwood's revision papers," Netherlands Journal of Zoology, vol. 27, no. 4, pp. 333-389, 1976.

[80] K. F. Liem, "Modulatory multiplicity in the functional repertoire of the feeding mechanism in cichlid fishes. I. Piscivores," Journal of Morphology, vol. 158, no. 3, pp. 323360, 1978.

[81] L. Rüber, E. Verheyen, and A. Meyer, "Replicated evolution of trophic specializations in an endemic cichlid fish lineage from Lake Tanganyika," Proceedings of the National Academy of Sciences of the United States of America, vol. 96, no. 18, pp. 10230-10235, 1999.

[82] L. Postl, J. Herler, C. Bauer, M. Maderbacher, L. Makasa, and C. Sturmbauer, "Geometric morphometrics applied to viscerocranial bones in three populations of the Lake Tanganyika cichlid fish Tropheus moorii," Journal of Zoological Systematics and Evolutionary Research, vol. 46, no. 3, pp. 240248, 2008.

[83] M. Hori, "Frequency-dependent natural selection in the handedness of scale-eating cichlid fish," Science, vol. 260, no. 5105, pp. 216-219, 1993.

[84] Y. Takeuchi and M. Hori, "Behavioural laterality in the shrimp-eating cichlid fish Neolamprologus fasciatus in Lake Tanganyika," Animal Behaviour, vol. 75, no. 4, pp. 1359-1366, 2008.

[85] K. F. Liem and D. J. Stewart, "Evolution of the scale-eating cichlid fishes of Lake Tanganyika: a generic revision with a description of a new species," Bulletin Museum of Comparative Zoology, vol. 147, no. 7, pp. 319-350, 1976.

[86] M. Hori, H. Ochi, and M. Kohda, "Inheritance pattern of lateral dimorphism in two cichlids (a scale eater, Perissodus microlepis, and an Herbivore, Neolamprologus moorii) in Lake Tanganyika," Zoological Science, vol. 24, no. 5, pp. 486-492, 2007.

[87] T. A. Stewart and R. C. Albertson, "Evolution of a unique predatory feeding apparatus: functional anatomy, development and a genetic locus for jaw laterality in Lake Tanganyika scale-eating cichlids," BMC Biology, vol. 8, article 8, 2010.

[88] T. J. Van Dooren, H. A. van Goor, and M. van Putten, "Handedness and asymmetry in scale-eating cichlids: antisymmetries of different strength," Evolution, vol. 64, no. 7, pp. 2159-2165, 2010.

[89] S. Takahashi and M. Hori, "Unstable evolutionarily stable strategy and oscillation: a model of lateral asymmetry in scale-eating cichlids," American Naturalist, vol. 144, no. 6, pp. 1001-1020, 1994.

[90] M. Nakajima, H. Matsuda, and M. Hori, "A population genetic model for lateral dimorphism frequency in fishes," Population Ecology, vol. 47, no. 2, pp. 83-90, 2005.

[91] T. Takahashi and M. Hori, "Evidence of disassortative mating in a Tanganyikan cichlid fish and its role in the maintenance of intrapopulation dimorphism," Biology Letters, vol. 4, no. 5, pp. 497-499, 2008.

[92] R. C. Albertson, J. T. Streelman, and T. D. Kocher, "Genetic basis of adaptive shape differences in the cichlid head," Journal of Heredity, vol. 94, no. 4, pp. 291-301, 2003.

[93] R. C. Albertson, J. T. Streelman, T. D. Kocher, and P. C. Yelick, "Integration and evolution of the cichlid mandible: the molecular basis of alternate feeding strategies," Proceedings of the National Academy of Sciences of the United States of America, vol. 102, no. 45, pp. 16287-16292, 2005.

[94] K. J. Parsons and R. C. Albertson, "Roles for Bmp4 and CaM1 in shaping the jaw: evo-devo and beyond," Annual Review of Genetics, vol. 43, pp. 369-388, 2009.

[95] P. S. Lobel, "Possible species specific courtship sounds by two sympatric cichlid fishes in Lake Malawi, Africa," Environmental Biology of Fishes, vol. 52, no. 4, pp. 443-452, 1998.

[96] M. C. P. Amorim, M. E. Knight, Y. Stratoudakis, and G. F. Turner, "Differences in sounds made by courting males of three closely related Lake Malawi cichlid species," Journal of Fish Biology, vol. 65, no. 5, pp. 1358-1371, 2004.

[97] A. N. Rice and P. S. Lobel, "The pharyngeal jaw apparatus of the Cichlidae and Pomacentridae: function in feeding and sound production," Reviews in Fish Biology and Fisheries, vol. 13, no. 4, pp. 433-444, 2004.

[98] M. C. P. Amorim, J. M. Simões, P. J. Fonseca, and G. F. Turner, "Species differences in courtship acoustic signals among five Lake Malawi cichlid species (Pseudotropheus spp.)," Journal of Fish Biology, vol. 72, no. 6, pp. 1355-1368, 2008.

[99] L. Rüber and D. C. Adams, "Evolutionary convergence of body shape and trophic morphology in cichlids from Lake Tanganyika," Journal of Evolutionary Biology, vol. 14, no. 2, pp. 325-332, 2001.

[100] P. W. Webb, "Body form, locomotion and foraging in aquatic vertebrates," Integrative and Comparative Biology, vol. 24, no. 1, pp. 107-120, 1984.

[101] C. S. Wardle, J. J. Videler, and J. D. Altringham, “Tuning in to fish swimming waves: body form, swimming mode and muscle function," The Journal of Experimental Biology, vol. 198, no. 8, pp. 1629-1636, 1995.

[102] J. D. Altringham and D. J. Ellerby, "Fish swimming: Patterns in muscle function," Journal of Experimental Biology, vol. 202, no. 23, pp. 3397-3403, 1999. 
[103] T. Takahashi and M. Hori, "Description of a new Lake Tanganyikan cichlid fish of the genus Cyprichromis (Perciformes: Cichlidae) with a note on sexual dimorphism," Journal of Fish Biology, vol. 68, supplement B, pp. 174-192, 2006.

[104] J. Herler, M. Kerschbaumer, P. Mitteroecker, L. Postl, and C. Sturmbauer, "Sexual dimorphism and population divergence in the Lake Tanganyika cichlid fish genus Tropheus," Frontiers in Zoology, vol. 7, article 4, 2010.

[105] M. Maderbacher, C. Bauer, J. Herler, L. Postl, L. Makasa, and C. Sturmbauer, "Assessment of traditional versus geometric morphometrics for discriminating populations of the Tropheus moorii species complex (Teleostei: Cichlidae), a Lake Tanganyika model for allopatric speciation," Journal of Zoological Systematics and Evolutionary Research, vol. 46, no. 2, pp. 153-161, 2008.

[106] M. Kerschbaumer, L. Postl, M. Koch, T. Wiedl, and C. Sturmbauer, "Morphological distinctness despite large-scale phenotypic plasticity-analysis of wild and pond-bred juveniles of allopatric populations of Tropheus moorii," Naturwissenschaften, vol. 98, no. 2, pp. 125-134, 2011.

[107] D. Schluter, T. D. Price, and L. Rowe, "Conflicting selection pressures and life history trade-offs," Proceedings of the Royal Society B, vol. 246, no. 1315, pp. 11-17, 1991.

[108] W. U. Blanckenhorn, "The quarterly review of biology: the evolution of body size: what keeps organisms small?" Quarterly Review of Biology, vol. 75, no. 4, pp. 385-407, 2000.

[109] T. Takahashi, "Morphological and genetic distinctness of rock and shell-bed dwelling Telmatochromis (Teleostei, Cichlidae) in the south of Lake Tanganyika suggest the existence of two species," Journal of Fish Biology, vol. 65, no. 2, pp. 419$435,2004$.

[110] T. Takahashi, K. Watanabe, H. Munehara, L. Rüber, and M. Hori, "Evidence for divergent natural selection of a Lake Tanganyika cichlid inferred from repeated radiations in body size," Molecular Ecology, vol. 18, no. 14, pp. 3110-3119, 2009.

[111] D. Schütz and M. Taborsky, "Giant males or dwarf females: what determines the extreme sexual size dimorphism in Lamprologus callipterus?" Journal of Fish Biology, vol. 57, no. 5, pp. 1254-1265, 2000.

[112] D. Schütz and M. Taborsky, "The influence of sexual selection and ecological constraints on an extreme sexual size dimorphism in a cichlid," Animal Behaviour, vol. 70, no. 3, pp. 539-549, 2005.

[113] D. Schütz, G. A. Parker, M. Taborsky, and T. Sato, "An optimality approach to male and female body sizes in an extremely size-dimorphic cichlid fish," Evolutionary Ecology Research, vol. 8, no. 8, pp. 1393-1408, 2006.

[114] C. Vreys and N. K. Michiels, "Flatworms flatten to size up each other," Proceedings of the Royal Society B, vol. 264, no. 1388, pp. 1559-1564, 1997.

[115] K. Johannesson, E. Rolan-Alvarez, and A. Ekendahl, "Incipient reproductive isolation between two sympatric morphs of the intertidal snail Littorina saxatilis," Evolution, vol. 49, no. 6, pp. 1180-1190, 1995.

[116] R. Elwood, J. Gibson, and S. Neil, "The amorous Gammarus: size assortative mating in G. pulex," Animal Behaviour, vol. 35, no. 1, pp. 1-6, 1987.

[117] L. K. Johnson, "Sexual selection in a brentid weevil," Evolution, vol. 36, no. 2, pp. 251-262, 1982.

[118] D. K. McLain and R. D. Boromisa, "Male choice, fighting ability, assortative mating and the intensity of sexual selection in the milkweed longhorn beetle, Tetraopes tetraophthalmus (Coleoptera, Cerambycidae)," Behavioral Ecology and Sociobiology, vol. 20, no. 4, pp. 239-246, 1987.
[119] G. Arnqvist, L. Rowe, J. J. Krupa, and A. Sih, "Assortative mating by size: a meta-analysis of mating patterns in water striders," Evolutionary Ecology, vol. 10, no. 3, pp. 265-284, 1996.

[120] K. R. McKaye, "Mate choice and size assortative pairing by the cichlid fishes of Lake Jiloá, Nicaragua," Journal of Fish Biology, vol. 29, supplement A, pp. 135-150, 1986.

[121] N. Kolm, "Male size determines reproductive output in a paternal mouthbrooding fish," Animal Behaviour, vol. 63, no. 4, pp. 727-733, 2002.

[122] D. H. Olson, A. R. Blaustein, and R. K. O'Hara, "Mating pattern variability among western toad (Bufo boreas) populations," Oecologia, vol. 70, no. 3, pp. 351-356, 1986.

[123] R. Shine, D. O'connor, M. P. Lemaster, and R. T. Mason, "Pick on someone your own size: ontogenetic shifts in mate choice by male garter snakes result in size-assortative mating," Animal Behaviour, vol. 61, no. 6, pp. 1133-1141, 2001.

[124] M. Olsson, "Male preference for large females and assortative mating for body size in the sand lizard (Lacerta agilis)," Behavioral Ecology and Sociobiology, vol. 32, no. 5, pp. 337341, 1993.

[125] B. T. Preston, I. R. Stevenson, J. M. Pemberton, D. W. Coltman, and K. Wilson, "Male mate choice influences female promiscuity in Soay sheep," Proceedings of the Royal Society B, vol. 272, no. 1561, pp. 365-373, 2005.

[126] A. Delestrade, "Sexual size dimorphism and positive assortative mating in Alpine choughs (Pyrrhocorax graculus)," Auk, vol. 118, no. 2, pp. 553-556, 2001.

[127] R. Cruz, M. Carballo, P. Conde-Padín, and E. RolánAlvarez, "Testing alternative models for sexual isolation in natural populations of Littorina saxatilis: indirect support for by-product ecological speciation?" Journal of Evolutionary Biology, vol. 17, no. 2, pp. 288-293, 2004.

[128] L. Nagel and D. Schluter, "Body size, natural selection, and speciation in sticklebacks," Evolution, vol. 52, no. 1, pp. 209218, 1998.

[129] U. Schliewen, K. Rassmann, M. Markmann, J. Markert, T. Kocher, and D. Tautz, "Genetic and ecological divergence of a monophyletic cichlid species pair under fully sympatric conditions in Lake Ejagham, Cameroon," Molecular Ecology, vol. 10, no. 6, pp. 1471-1488, 2001.

[130] R. Huber, M. J. Van Staaden, L. S. Kaufman, and K. F. Liem, "Microhabitat use, trophic patterns, and the evolution of brain structure in African cichlids," Brain, Behavior and Evolution, vol. 50, no. 3, pp. 167-182, 1997.

[131] A. A. Pollen, A. P. Dobberfuhl, J. Scace et al., "Environmental complexity and social organization sculpt the brain in Lake Tanganyikan cichlid fish," Brain, Behavior and Evolution, vol. 70, no. 1, pp. 21-39, 2007.

[132] J. B. Sylvester, C. A. Rich, Y. H. E. Loh, M. J. Van Staaden, G. J. Fraser, and J. T. Streelman, "Brain diversity evolves via differences in patterning," Proceedings of the National Academy of Sciences of the United States of America, vol. 107, no. 21, pp. 9718-9723, 2010.

[133] H. A. Hofmann, "Early developmental patterning sets the stage for brain evolution," Proceedings of the National Academy of Sciences of the United States of America, vol. 107, no. 22, pp. 9919-9920, 2010.

[134] T. Takahashi, "Comparative osteology of the infraorbitals in cichlid fishes (Osteichthyes: Teleostei: Perciformes) from Lake Tanganyika," Species Diversity, vol. 8, no. 1, pp. 1-26, 2003. 
[135] H. Bleckmann, "Role of the lateral line in fish behaviour," in Behaviour of Teleost Fishes, T. J. Pitcher, Ed., pp. 201-246, Chapman \& Hall, London, UK, 2nd edition, 1993.

[136] L. Persson and L. A. Greenberg, "Juvenile competitive bottlenecks: the perch (Perca fluviatilis)- roach (Rutilus rutilus) interaction," Ecology, vol. 71, no. 1, pp. 44-56, 1990.

[137] G. E. Hutchinson, "Homage to Santa Rosalia, or why are there so many kinds of animals?" American Naturalist, vol. 93, no. 870, pp. 145-159, 1959.

[138] E. E. Werner and J. F. Gilliam, "The ontogenetic niche and species interactions in size-structured populations," Annual Review of Ecology and Systematics, vol. 15, pp. 393-425, 1984.

[139] D. Griffiths, "Prey availability and the food of predators," Ecology, vol. 56, no. 5, pp. 1209-1214, 1975.

[140] S. T. Ross, "Trophic ontogeny of the leopard searobin, Prionotus scitulus (Pisces: Triglidae)," Fisheries Bulletin, vol. 76, pp. 225-234, 1978.

[141] G. D. Grossman, "Ecological aspects of ontogenetic shifts in prey size utilization in the bay goby (Pisces: Gobiidae)," Oecologia, vol. 47, no. 2, pp. 233-238, 1980.

[142] A. W. Stoner and R. J. Livingston, "Ontogenetic patterns in diet and feeding morphology in sympatric sparid fishes from seagrass meadows," Copeia, vol. 1984, no. 1, pp. 174-187, 1984.

[143] M. I. McCormick, "Ontogeny of diet shifts by microcarnicorous fish, Cheilodactylus spectabilis: relationships between feeding mechanics, microhabitat selection and growth," Marine Biology, vol. 132, no. 1, pp. 9-20, 1998.

[144] R. Svanbäck and P. Eklöv, "Effects of habitat and food resources on morphology and ontogenetic growth trajectories in perch," Oecologia, vol. 131, no. 1, pp. 61-70, 2002.

[145] B. S. Graham, D. Grubbs, K. Holland, and B. N. Popp, "A rapid ontogenetic shift in the diet of juvenile yellowfin tuna from Hawaii," Marine Biology, vol. 150, no. 4, pp. 647-658, 2007.

[146] E. E. Werner, "Species packing and niche complementarity in three sunfishes," American Naturalist, vol. 111, no. 979, pp. 553-578, 1977.

[147] E. E. Werner, G. G. Mittelbach, D. J. Hall, and J. F. Gilliam, "Experimental tests of optimal habitat use in fish: the role of relative habitat profitability," Ecology, vol. 64, no. 6, pp. 15251539, 1983.

[148] M. H. Olson, "Ontogenetic niche shifts in largemouth bass: variability and consequences for first-year growth," Ecology, vol. 77, no. 1, pp. 179-190, 1996.

[149] M. J. Neuman and K. W. Able, "Quantification of ontogenetic transitions during the early life of a flatfish, windowpane (Scophthalmus aquosus) (Pleuronectiformes Scophthalmidae)," Copeia, no. 3, pp. 597-609, 2002.

[150] F. Huysentruyt, B. Moerkerke, S. Devaere, and D. Adriaens, "Early development and allometric growth in the armoured catfish Corydoras aeneus (Gill, 1858)," Hydrobiologia, vol. 627, no. 1, pp. 45-54, 2009.

[151] G. G. Mittelbach and L. Persson, "The ontogeny of piscivory and its ecological consequences," Canadian Journal of Fisheries and Aquatic Sciences, vol. 55, no. 6, pp. 1454-1465, 1998.

[152] D. M. Post, "Individual variation in the timing of ontogenetic niche shifts in largemouth bass," Ecology, vol. 84, no. 5, pp. 1298-1310, 2003.

[153] A. Keast, "The piscivore feeding guild of fishes in small freshwater ecosystems," Environmental Biology of Fishes, vol. 12, no. 2, pp. 119-129, 1985.

[154] M. Hori, "Comparative study on the feeding ecology of thirteen species of Lamprologus (Teleostei; Cichlidae) coexisting at a rocky shore of Lake Tanganyika," Physiology and Ecology Japan, vol. 20, pp. 129-149, 1983.

[155] M. M. Gashagaza and M. Nagoshi, "Comparative study on the food habits of six species of Lamprologus (Osteichthyes: Cichlidae)," African Study Monographs, vol. 6, pp. 37-44, 1986.

[156] M. Yuma, "Food habits and foraging behaviour of benthivorous cichlid fishes in lake Tanganyika," Environmental Biology of Fishes, vol. 39, no. 2, pp. 173-182, 1994.

[157] M. Yuma, T. Narita, M. Hori, and T. Kondo, "Food resources of shrimp-eating cichlid fishes in Lake Tanganyika," Environmental Biology of Fishes, vol. 52, no. 1-3, pp. 371-378, 1998.

[158] B. R. Grant, "Evolution in Darwin's Finches: a review of a study on Isla Daphne Major in the Galápagos Archipelago," Zoology, vol. 106, no. 4, pp. 255-259, 2003.

[159] R. H. Robichaux, G. D. Carr, M. Liebman, and R. W. Pearcy, "Adaptive radiation of the Hawaiian silversword alliance (Compositae-Madiinae): ecological, morphological, and physiological diversity," Annals of the Missouri Botanical Garden, vol. 77, pp. 64-72, 1990.

[160] M. Kerschbaumer and C. Sturmbauer, "The utility of geometric morphometrics to elucidate pathways of cichlid fish evolution," International Journal of Evolutionary Biology, vol. 2011, Article ID 290245, 2011.

[161] M. J. H. Van Oppen, G. F. Turner, G. Rico et al., "Assortative mating among rock-dwelling cichlid fishes supports high estimates of species richness from Lake Malawi," Molecular Ecology, vol. 7, no. 8, pp. 991-1001, 1998.

[162] V. C. K. Couldridge and G. J. Alexander, "Color patterns and species recognition in four closely related species of Lake Malawi cichlid," Behavioral Ecology, vol. 13, no. 1, pp. 59-64, 2002.

[163] O. Seehausen, Y. Terai, I. S. Magalhaes et al., "Speciation through sensory drive in cichlid fish," Nature, vol. 455, no. 7213, pp. 620-626, 2008.

[164] M. Plenderleith, C. Van Oosterhout, R. L. Robinson, and G. F. Turner, "Female preference for conspecific males based on olfactory cues in a Lake Malawi cichlid fish," Biology Letters, vol. 1, no. 4, pp. 411-414, 2005.

[165] W. Salzburger, H. Niederstätter, A. Brandstätter et al., "Colour-assortative mating among populations of Tropheus moorii , a cichlid fish from Lake Tanganyika, East Africa," Proceedings of the Royal Society B, vol. 273, no. 1584, pp. 257266, 2006.

[166] B. Egger, B. Obermüller, E. Eigner, C. Sturmbauer, and K. M. Sefc, "Assortative mating preferences between colour morphs of the endemic Lake Tanganyika cichlid genus Tropheus," Hydrobiologia, vol. 615, no. 1, pp. 37-48, 2008.

[167] B. Egger, K. Mattersdorfer, and K. M. Sefc, "Variable discrimination and asymmetric preferences in laboratory tests of reproductive isolation between cichlid colour morphs," Journal of Evolutionary Biology, vol. 23, no. 2, pp. 433-439, 2010.

[168] A. Rossiter, "The cichlid fish assemblages of Lake Tanganyika: ecology, behaviour and evolution of its species flocks," Advances in Ecological Research, vol. 26, pp. 187-252, 1995.

[169] C. A. Scholz, J. W. King, G. S. Ellis, P. K. Swart, J. C. Stager, and S. M. Colman, "Paleolimnology of Lake Tanganyika, East Africa, over the past $100 \mathrm{k} \mathrm{yr}$," Journal of Paleolimnology, vol. 30, no. 2, pp. 139-150, 2003.

[170] A. S. Cohen, J. R. Stone, K. R. M. Beuning et al., "Ecological consequences of early Late Pleistocene megadroughts in 
tropical Africa," Proceedings of the National Academy of Sciences of the United States of America, vol. 104, no. 42, pp. 16422-16427, 2007.

[171] M. M. McGlue, K. E. Lezzar, A. S. Cohen et al., "Seismic records of late Pleistocene aridity in Lake Tanganyika, tropical East Africa," Journal of Paleolimnology, vol. 40, no. 2, pp. 635-653, 2008.

[172] H. Ochi, Y. Yanagisawa, and K. Omori, "Intraspecific broodmixing of the cichlid fish Perissodus microlepis in Lake Tanganyika," Environmental Biology of Fishes, vol. 43, no. 2, pp. 201-206, 1995.

[173] H. Ochi and Y. Yanagisawa, "Interspecific brood-mixing in Tanganyikan cichlids," Environmental Biology of Fishes, vol. 45, no. 2, pp. 141-149, 1996.

[174] Y. Yanagisawa, H. Ochi, and A. Rossiter, "Intra-buccal feeding of young in an undescribed Tanganyikan cichlid Microdontochromis sp.", Environmental Biology of Fishes, vol. 47, no. 2, pp. 191-201, 1996.

[175] M. Hori, "Structure of littoral fish communities organized by their feeding activities," in Fish Communities in Lake Tanganyika, H. Kawanabe, M. Hori, and M. Nagoshi, Eds., pp. 275-298, Kyoto University Press, Kyoto, Japan, 1997.

[176] M. Kohda, "Interspecific society among herbivorous cichlid fishes," in Fish Communities in Lake Tanganyika, H. Kawanabe, M. Hori, and M. Nagoshi, Eds., pp. 105-120, Kyoto University Press, Kyoto, Japan, 1997.

[177] K. Takamura, "Foraging dependence in the littoral fish community," in Fish Communities in Lake Tanganyika, H. Kawanabe, M. Hori, and M. Nagoshi, Eds., pp. 137-148, Kyoto University Press, Kyoto, Japan, 1997.

[178] M. Kohda, J. Y. Shibata, S. Awata et al., "Niche differentiation depends on body size in a cichlid fish: a model system of a community structured according to size regularities," Journal of Animal Ecology, vol. 77, no. 5, pp. 859-868, 2008.

[179] Y. Takeuchi, H. Ochi, M. Kohda, D. Sinyinza, and M. Hori, "A 20-year census of a rocky littoral fish community in Lake Tanganyika," Ecology of Freshwater Fish, vol. 19, no. 2, pp. 239-248, 2010. 

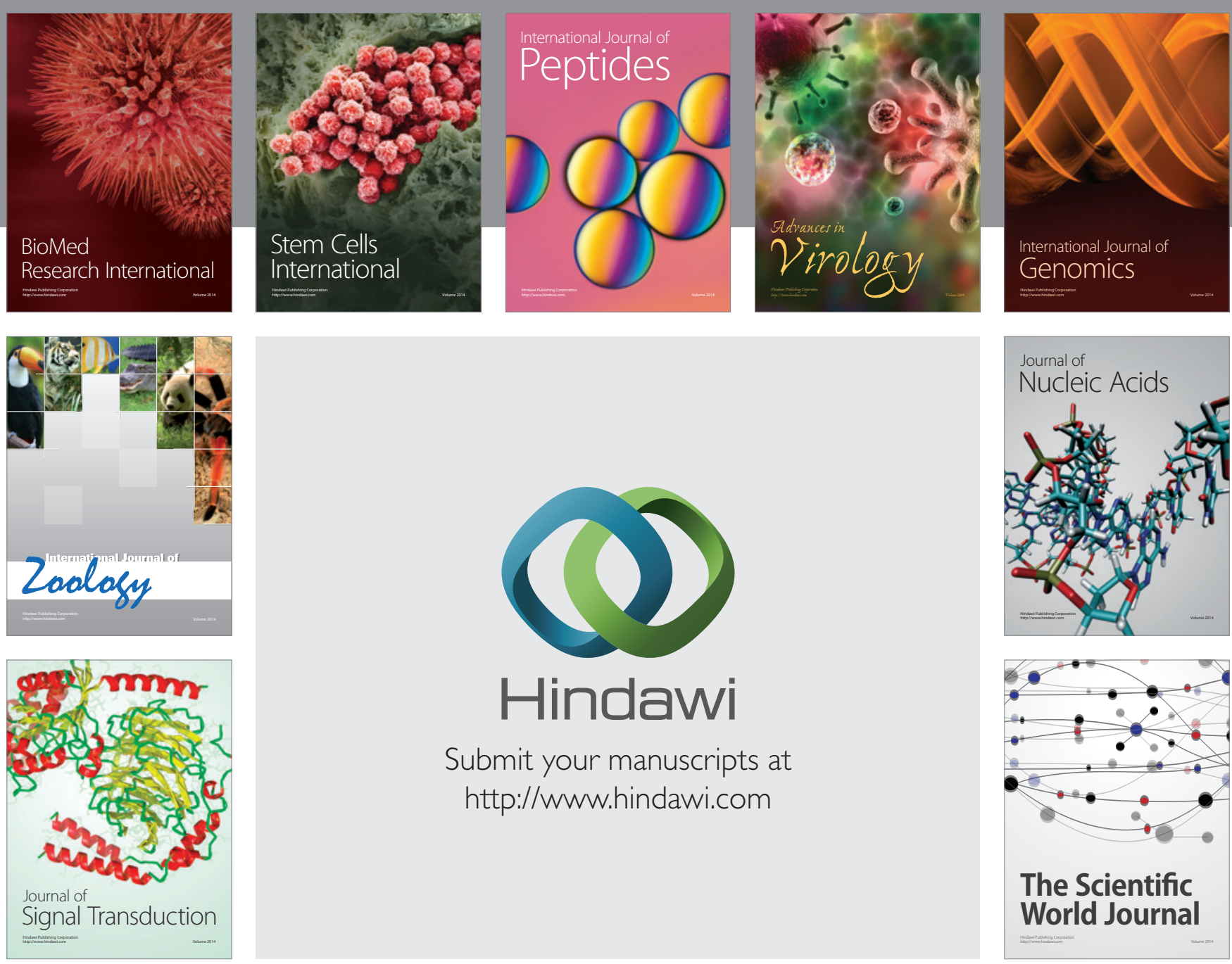

Submit your manuscripts at

http://www.hindawi.com
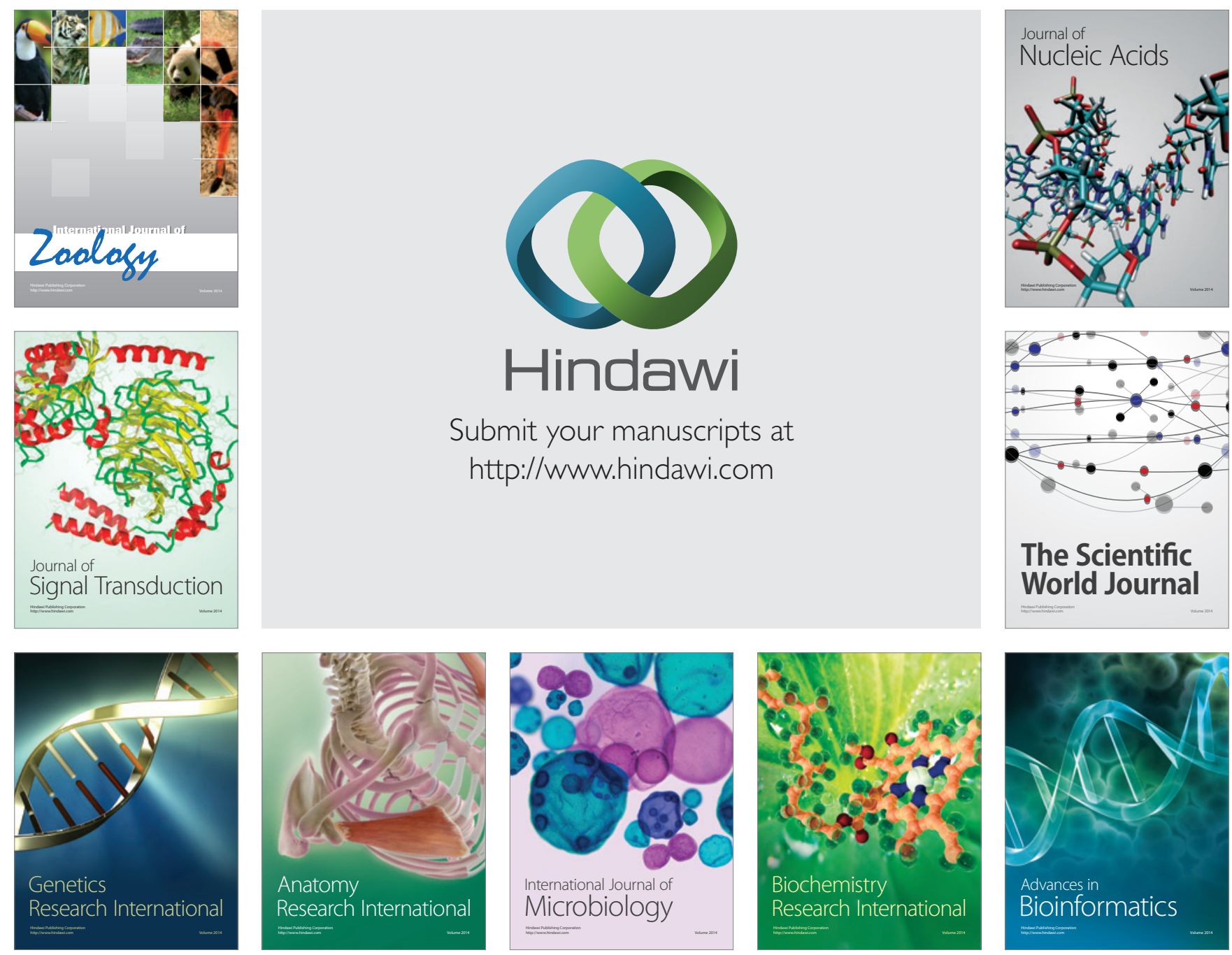

The Scientific World Journal
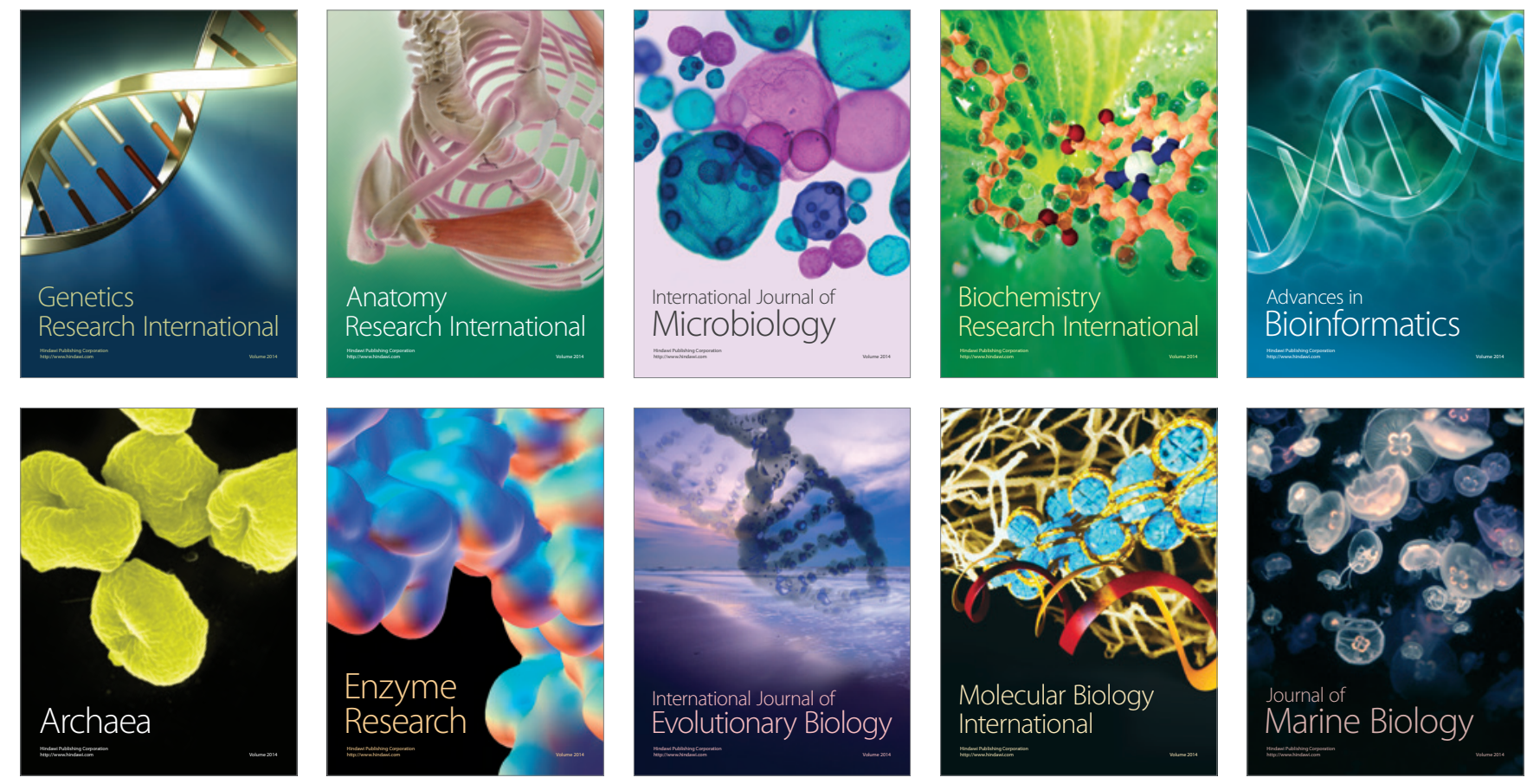